\title{
Morbidity And Mortality of Low Birth weight Newborns Admitted in Sncu/Nicui in A Tertiary Care Hospital.
}

\author{
Dr.G.V.Ramadevi ${ }^{1}$,Dr.K.V.Ramanarao ${ }^{2}$,Dr.V.Veeraratnakarreddy ${ }^{3}$

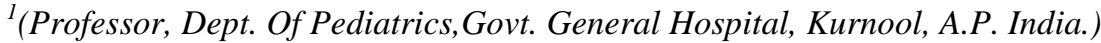 \\ ${ }_{2}^{2}$ (Assistant Professor, Dept. Of Pediatrics, Govt. General Hospital, Kurnool, A.P. India.) \\ ${ }_{3}^{3}$ (Consultant Pediatrician, APMC.63453, Kurnool, A.P. India.)
}

\begin{abstract}
Aim of the present study is factors that affecting the morbidity and mortality in low birth weight $(L B W)$ babies born with birth weight less than 2500gms. Study is a longitudinal, observational and intervention study done on babies weighing less than 2500 gms irrespective of gestational age admitted to SNCU / NICU, Government General Hospital, Kurnool, from January 2012 to December 2012. At admission Clinical details of all babies were recorded, investigated and managed as per the standard protocols, after exclusion criteria a total of 419 LBW babies (17.5\% of all admissions) were included in the study, The incidence of LBW was $52.9 \%$ of total NICU admissions. Of the 419 cases 138 were died. Mortality rate was 32.79\%; mortality observed was more in ELBW and VLBW babies. In the study major constituents of morbidity was sepsis ( $45.1 \%)$ followed by RDS (20.4\%). The remaining 281 cases followed up till 6 months regularly. The babies were periodically checked for weight, head circumference, developmental milestones. 9 cases out of 281 shown morbidity in the form of cerebral palsy (3/9,33.3\%), poor weight gain (2/9, 22.2\%), post meningitis sequel (2/9, $22.2 \%)$, recurrent seizures $(2 / 9,22.2 \%)$ implicating birth asphyxia as a predominant factor causing morbidity. So we conclude that incidence of low birth babies is relatively high in male babies than females, survival rate improving with increased gestational age and increased weight of the babies. The mortality pattern in the study was in the following order, Sepsis (42\%), RDS (31.1\%) and Birth asphyxia (10.9\%) etc.
\end{abstract}

Keywords: Birth weight, low birth weight, gestational age, morbidity and mortality.

\section{Introduction}

Low birth weight (LBW) is one of the most serious challenges in Maternal and Child Health in developing countries. The lower the birth weight the lower is the survival chances. WHO estimates that globally about 25 million LBW babies were born at each year, consisting 17 percent of all live births, nearly 95 percent of them in developing countries. In India currently 8 million LBW infants are born each year which constitutes $40 \%$ of global burden the highest for any country. ${ }^{1,2,3}$ In India according to National Family Health Survey :3 (2010), prevalence of low birth weight (LBW) babies is $21.5 \%$. LBW is a major cause of infant mortality and is considered as a sensitive index of Nations health and development. LBW is known to increase the risk for major disabilities such as cerebral palsy and mental retardation, anemia of prematurity, Kernicterus, PDA, respiratory distress, apnea, retinopathy, entero colitis, but researchers now showing evidences that LBW also contributes to minor difficulties in motor skills and in thinking, learning and memory. In view of this, to know the various factors affecting the morbidity and mortality in LBW newborns and burden of complications in relation to morbidity and mortality the present study is conducted in the Special newborn care unit (SNCU) of Govt. General Hospital, Kurnool Medical College, Kurnool.

\section{Material And Methods}

This longitudinal, observational and intervention study was done on babies weighing less than 2500 gms irrespective of gestational age ${ }^{5,6,7}$ admitted to SCNU/ NICU, Department of Pediatrics, Govt. General Hospital, Kurnool, from January 2012 to December 2012. The newborns were mostly referred from peripheral hospitals for better care. Study population includes a total of 419 cases of LBW newborns of less than $2500 \mathrm{gms}$ chosen among 1267 cases admitted. Information was recorded on a structured proforma by questionnaire method. Information related to age, sex, the problem with which newborn admitted, antenatal, natal, postnatal history, treatment history, socio economic status of parents, etc were considered.

A thorough clinical examination was done on the day of admission followed by necessary investigations and standard protocol treatment followed. The study was approved by the Ethics Committee of the hospital and informed consent of the parents was obtained.

\section{Results}

A total of 2391 cases were admitted to SNCU, during the study period. Out of 2391 admissions 1267 were LBW babies admitted both in inborn and outborn. The incidence of low birth weight was $52.9 \%$ of total 
SNCU admissions. Of the 1267 LBW babies 419 cases were selected for study. Of the 419 cases 138 cases were died, mortality rate was $32.9 \%$, and the number of babies survived were 281cases, survival rate was $67.1 \%$. Mortality observed was more in extremely low birth weight (ELBW) and Very low birth weight (VLBW) mainly. Out of 419 cases studied 233 (55.6\%) were male babies and 186 (44.4\%) were females. Male to Female ratio is $1.25: 1$.

Graph 1: LBW and Other cases admission ratio

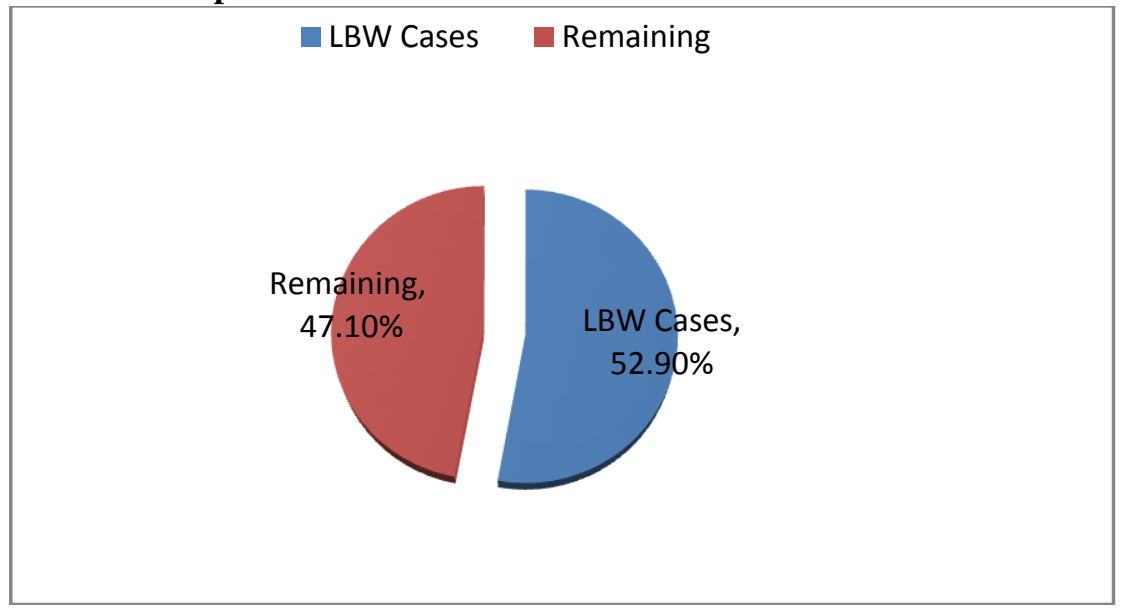

Graph 2: Male to Female babies admission ratio

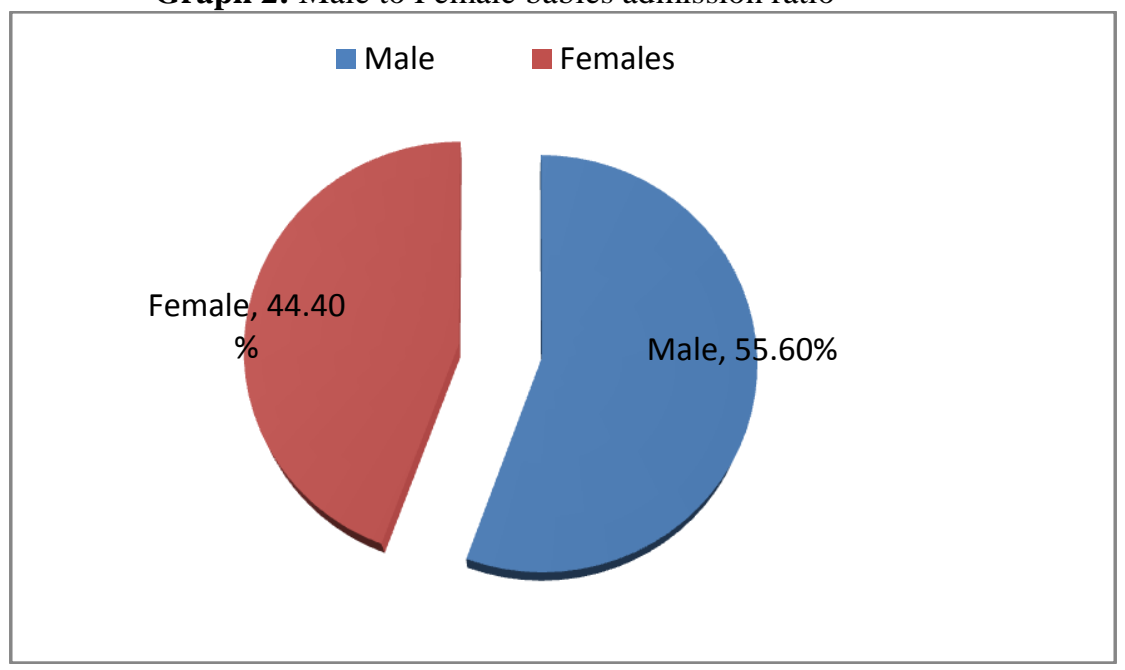

Graph 3: Survival and Mortality ratio

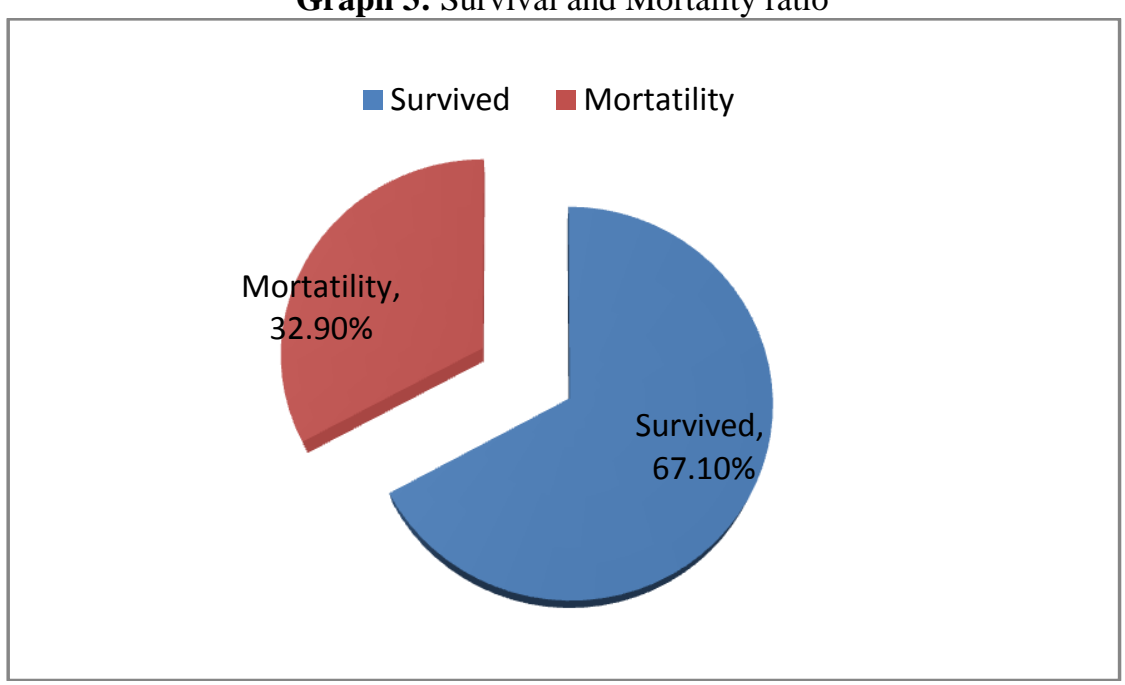


Table 1 : Outcome in relation to the gestational age :

\begin{tabular}{|l|l|l|l|}
\hline Gestational Age & Death & Alive & Total \\
\hline$<26$ weeks & $5(83.3 \%)$ & $1(16.7 \%)$ & 6 \\
\hline $26-30$ weeks & $37(58.7 \%)$ & $26(41.3)$ & 63 \\
\hline $31-34$ weeks & $53(36.3 \%)$ & $93(63.7 \%)$ & 146 \\
\hline $35-37$ weeks & $54(25.1 \%)$ & $161(74.9 \%)$ & 215 \\
\hline Total & 138 & 281 & 419 \\
\hline
\end{tabular}

Out of 6 babies who were less than 26 weeks of gestational age only one baby (16.7\%) survived. 63 babies were in the gestational age of 26-30 weeks with mortality and survival rates of $58.7 \%$ and $41.3 \%$ respectively. 146 babies were of 31-34 weeks with mortality and survival rates were of $36.3 \%$ and $63.7 \%$ respectively. Those who are nearing term i.e., 35-37 weeks the mortality and survival rates were of 54(25.1\%) and $161(74.9 \%)$ respectively. The mortality is very high in less than 26 weeks against survival $(83.3 \%$ vs. $16.7 \%)$.

Graph 4: The Outcome in relation to gestational age

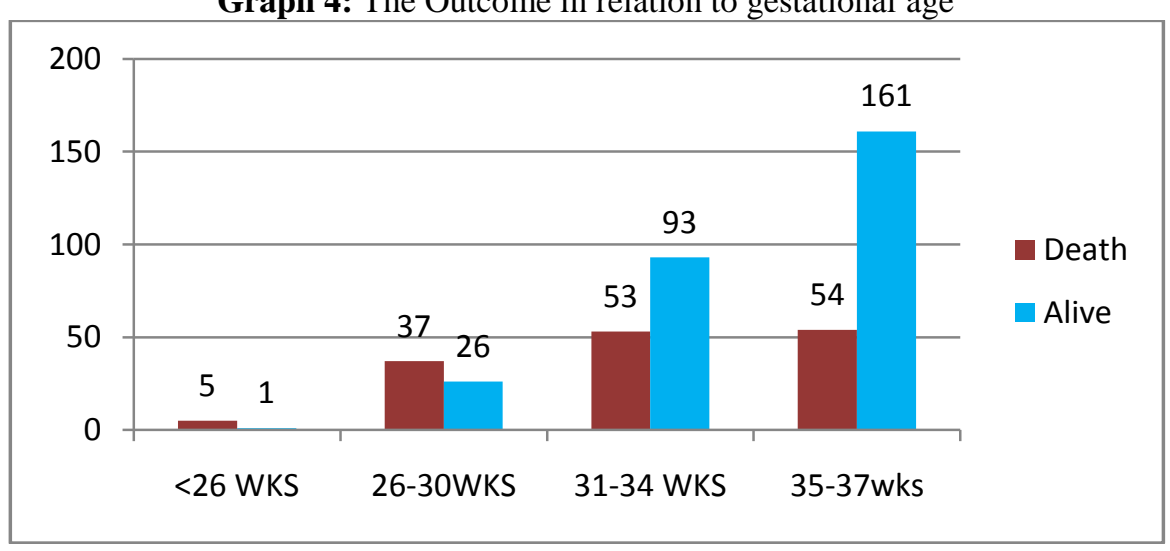

Table2: Outcome in relation to birth weight

\begin{tabular}{|c|c|c|c|}
\hline \multirow{2}{*}{ Weight } & \multicolumn{2}{|c|}{ Outcome } & \multirow{2}{*}{ Total } \\
\cline { 2 - 3 } & Death & Alive & 36 \\
\hline$<1000 \mathrm{gms}$ & $24(66.6 \%)$ & $12(33.4 \%)$ & 124 \\
\hline $1000-1499 \mathrm{gms}$ & $55(44.4 \%)$ & $69(55.6 \%)$ & 155 \\
\hline $1500-1999 \mathrm{gms}$ & $39(25.2 \%)$ & $116(74.8)$ & 104 \\
\hline $2000-2499 \mathrm{gms}$ & $20(19.2 \%)$ & $84(80.8 \%)$ & 419 \\
\hline Total & 138 & 281 & \\
\hline
\end{tabular}

Graph 5: Outcome in relation to birth weight

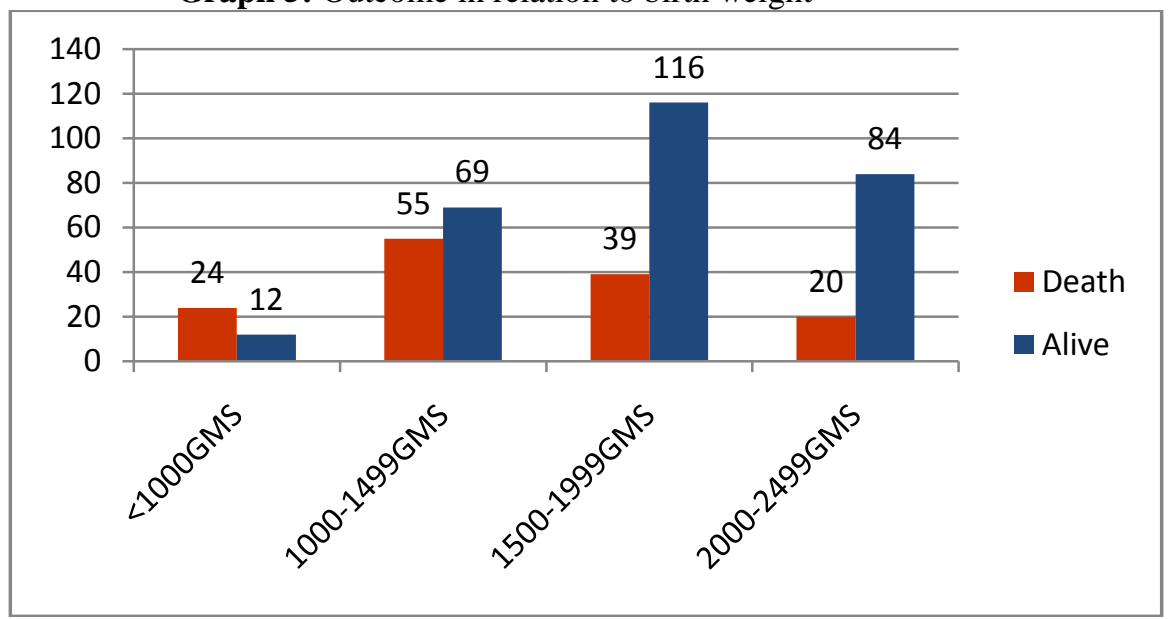

The present table shows outcome of LBW babies in relation to birth weight. Out of 36 babies weighing less than $1000 \mathrm{gms}$ more death rate was noted i.e., 24(66.6\%), survival rate was only $12(33.4 \%)$, those weighing 1000-1499 gms the death and survival rates were $44.4 \%$ and $55.6 \%$ respectively. The death and survival rates in 1500-1999 gms were $25.2 \%$ and $74.8 \%$ respectively; in 2000-2499 gms the death and survival rates were $19.2 \%$ and $80.8 \%$ respectively. Emphasizing the need for care of those weighing less than $1500 \mathrm{gms}$. 
Morbidity and Mortality of Low Birth Weight Newborns admitted in .....

Table 3: Presenting complaint vs. birth weight:

\begin{tabular}{|c|c|c|c|c|c|}
\hline Presenting complaint & $<\mathbf{1 0 0 0}$ gms & $\mathbf{1 0 0 0 - 1 4 9 9}$ gms & $\begin{array}{c}\mathbf{1 5 0 0 - 1 9 9 9} \\
\text { gms }\end{array}$ & $\mathbf{2 0 0 0 - 2 4 9 9}$ gms & Total \\
\hline Poor Cry & $8(22.2 \%)$ & $14(11.2 \%)$ & $11(7 \%)$ & $10(9.6 \%)$ & $43(10.2 \%)$ \\
\hline RD & $23(63.8 \%)$ & $67(54 \%)$ & $61(39.3 \%)$ & $34(32.6 \%)$ & $\begin{array}{c}185(44.1 \\
\%)\end{array}$ \\
\hline Seizures & 0 & $5(4 \%)$ & $24(15.4 \%)$ & $25(24 \%)$ & $54(12.9 \%)$ \\
\hline Poor Feeding & $4(11 \%)$ & $27(21.7 \%)$ & $44(28.3 \%)$ & $26(25 \%)$ & $\begin{array}{c}101(24.1 \\
\%)\end{array}$ \\
\hline Jaundice & 0 & $6(4.8 \%)$ & $10(6.5 \%)$ & $8(7.7 \%)$ & $24(5.7 \%)$ \\
\hline Bleeding & 1 & 0 & 4 & 1 & 6 \\
\hline Distension & 0 & 0 & 1 & 0 & 1 \\
\hline Apnea & 0 & 5 & 0 & 0 & 5 \\
\hline Total & 36 & 124 & 155 & 104 & 419 \\
\hline
\end{tabular}

This table shows the presenting complaint in various LBW babies. In Those weighing less than $1000 \mathrm{gms}$, Out of 36 babies $23(63.8 \%)$ babies were with respiratory distress, poor cry $8(22.2 \%)$. In those weighing 1000-1499gms out of 124 members 67(54\%) were with respiratory distress, 27(21.7\%) were with poor feeding and $14(11.2 \%)$ were with poor cry. Those weighing 1500-1999gms again respiratory distress forms the major proportion 61(39.3\%), 44(28.3\%) with poor feeding and 24(15.4\%) with seizures. In 2000-2499 groups Respiratory distress 34(32.6\%); seizures and poor feeding sharing almost equal distribution $24 \%$ and $25 \%$ respectively. Among $419 \mathrm{LBW}$ babies Respiratory distress forms the predominant presenting complaint (44.1\%) the same is seen in all other weighing babies followed by poor feeding $(24.1 \%)$ and poor cry $(10.2 \%)$.

Table 4: Diagnosis vs. weight of the Newborn

\begin{tabular}{|c|c|c|c|c|c|}
\hline Diagnosis & $<\mathbf{1 0 0 0}$ gms & $\begin{array}{c}\mathbf{1 0 0 0 - 1 4 9 9} \\
\text { gms }\end{array}$ & $\mathbf{1 5 0 0 - 1 9 9 9} \mathbf{g m s}$ & $\begin{array}{c}\mathbf{2 0 0 0 - 2 4 9 9} \\
\text { gms }\end{array}$ & Total \\
\hline HT \& HG & $1(14.2 \%)$ & $3(42.9 \%)$ & $3(42.9 \%)$ & 0 & 7 \\
\hline Sepsis & $5(2.6 \%)$ & $54(28.5 \%)$ & $88(46.5 \%)$ & $42(22.2 \%)$ & 189 \\
\hline HB & 0 & $5(17.2 \%)$ & $15(51.7 \%)$ & $9(31.1 \%)$ & 29 \\
\hline RDS & $23(27.1 \%)$ & $51(60 \%)$ & $11(12.9 \%)$ & 0 & 85 \\
\hline HIE & 2 & 5 & $15(32.6 \%)$ & $24(52.1 \%)$ & 46 \\
\hline MAS & 0 & 1 & 4 & $9(64.2 \%)$ & 14 \\
\hline TTN & 0 & 0 & 4 & $10(71.4 \%)$ & 14 \\
\hline CA & 2 & 2 & 8 & 9 & 21 \\
\hline Apnea & 0 & 2 & 0 & 0 & 2 \\
\hline HDN & 0 & 0 & 5 & 0 & 5 \\
\hline Seizures & 3 & 1 & 2 & 1 & 7 \\
\hline Total & 36 & 124 & 155 & 104 & 419 \\
\hline
\end{tabular}

Out of 7 cases with Hypoglycemia (HG) and Hypothermia (HT) only 01(14.2\%) baby weighing less than 1000gms present. 3(42.9\%) babies each fall under 1000-1499 and 1500-1999gms. None of the babies weighing more than $2000 \mathrm{gms}$ presented with this. Out of 189 babies presented with sepsis, $5(2.64 \%)$ babies weighing less than $1000 \mathrm{gms}, 54(28.5 \%)$ babies were present in the $1000-1499 \mathrm{gms}, 1500-1999 \mathrm{gms}$ were 88 $(46.5 \%)$ and $42(22.6 \%)$ were weighing in between 2000-2499gms. Out of 29 babies with Hyperbilirubinemia (HB) none were present in less than 1000gms, 5 (17.2\%) babies were in between 1000-1499gms, 15(51.7\%) were in the group of 1500-1999gms and $9(31.1 \%$ ) babies were in between 2000-2499gms. Out of 85 cases with Respiratory distress syndrome(RDS) $23(21.7 \%$ ) babies were in the less than $1000 \mathrm{gms}, 51(60 \%)$ babies were in the range of 1000-1499gms, 11(12.9\%) were in the range of 1500-1999gms. Among Birth asphyxia (BA/HIE), MAS and TTN, majority were in the range of 2000-2499gms $(52.1 \%, 64.2 \%$ and $74.1 \%)$ respectively.In less than $1000 \mathrm{gms}$ (ELBW) babies it shows Respiratory distress syndrome is the predominant morbidity factor $(63.8 \%)$ followed by Sepsis (13.8\%). In babies weighing 1000-1499gms (VLBW) sepsis and respiratory distress syndrome (43.5\% and 41.4\%) becoming the predominant ones. In 1500 to $1999 \mathrm{gm}$ babies sepsis is the predominant diagnosis (56.7\%) followed by hyperbilirubinemia and birth asphyxia sharing equally i.e., 9.7\% respectively. In 2000-2499gms sepsis (40.3\%), birth asphyxia (23\%), MAS \& TTN sharing with $8.7 \%$ and $9.6 \%$ respectively.

\section{Discussion}

The present study was conducted in the SNCU/NICU, Department of Pediatrics, Government General Hospital, Kurnool Medical College, Kurnool. A.P., during the period from January 2012 to December 2012. Out of 2391 admissions 1267 were low birth weight babies admitted both from inborn and out born, of which 419 cases were selected after excluding left against medical advice and not willing for participation in study. The incidence of low birth weight observed in the study was $52.9 \%$ of total NICU admissions of babies. LBW incidence is relatively higher in male babies when compared to female babies. The gender distribution 
among low birth weight group is comparable with Emel altuncu et $\mathrm{al}^{8}$, Kayastha et $\mathrm{al}^{9}$. In the study of Emel altuncu et $\mathrm{al}^{8}$ male preponderance is high when compared to female $(53.6 \%$ vs. $44.6 \%)$ which is also seen Kayastha et $\mathrm{al}^{9}$ (52\% vs. $\left.48 \%\right)$. In the current study also the similar results obtained (55.6\% vs. $\left.45.4 \%\right)$.

ELBW $(<1000 \mathrm{gms})$ incidence is relatively high in the current study $(8.6 \%)$ which is more when compared to Emel altuncu et $\mathrm{al}^{8}(3.3 \%)$ and Kayastha et $\mathrm{al}^{9}(4.1 \%)$ depicting that the burden of ELBW is relatively high in the current study casing more burden of morbidity and mortality. VLBW (1000-1500gms) incidence is also relatively high in the current study i.e., $(29.5 \%)$ when compared to Emel altuncu et al ${ }^{8}(10.7 \%)$ and Kayastha et $\mathrm{al}^{9}(8.7 \%)$.The incidence of those babies with more than $2000 \mathrm{gms}$ is high in the Emel altuncu et $\mathrm{al}^{8}$ and Kayastha et $\mathrm{al}^{9}$ when compared to current study.

The problem of extreme prematurity i.e. less than 28 weeks of gestational age is also very high in the current study which is comparable with Were $\mathrm{FN}$ et al ${ }^{10}$ i.e., $\left(7.3 \%\right.$ vs. $9 \%$, which is less in the Kayastha et $\mathrm{al}^{9}$ (3\%). Those born in between 29 to 32 weeks were in the order of $22.2 \%, 16.5 \%$ and $29 \%$ in the Present study, Kayastha et $\mathrm{al}^{9}$ and Were FN et $\mathrm{al}^{10}$ respectively. The low birth weight babies nearing term that lies in between 33 to 36 weeks were in the order of $42.7 \%, 33.5 \%$ and $69 \%$ in the Present study, Kayastha et $\mathrm{al}^{9}$ and Were FN et $\mathrm{al}^{10}$ respectively, Indicating more of near term babies being born in Were FN et al study. The overall survival of extremely low birth weight babies (<1000gms), is almost zero percent on Were FN et $\mathrm{al}^{10}$ study, where as in Daynia E. ballot et $\mathrm{al}^{11}$ study is $35 \%$. where as in current study it comes around $33 \%$ matching with the Daynia E. ballot et $\mathrm{al}^{11}$ study and is better than Were FN et $\mathrm{al}^{10}$ study. The survival of ELBW infants in the present review of $33 \%$ was less than that of other developing countries, such as Thailand ${ }^{12}$ and Jamaica ${ }^{13}$.

The survival pattern in VLBW in the current study is about (66.4\%) which is a bit less when compared to Daynia E. ballot et al study ${ }^{11}(70.5 \%)$ and Velaphi et $\mathrm{al}^{14}(72 \%)$. Out of 419 cases, excluding the babies died (138 cases) 281 cases followed up till 6 months regularly. The babies were periodically checked for weight, head circumference, developmental milestones. 9 cases out of 281 shown morbidity in the form of cerebral palsy $(3 / 9,33.3 \%)$, poor weight gain $(2 / 9,22.2 \%)$, post meningitis sequel $(2 / 9,22.2 \%)$, recurrent seizures $(2 / 9$, $22.2 \%$ ) implicating birth asphyxia, as a predominant factor causing morbidity.

\section{Conclusion}

Incidence of low birth weight is $52.9 \%$; Incidence of low birth weight is relatively higher in male babies when compared to female babies. The survival rate in low birth weight babies improving with increased gestational age. The survival rate is increasing with increased birth weight of babies. The mortality pattern in the study was in the following order, Sepsis(42\%), $\operatorname{RDS}(31.1 \%)$, Birth asphyxia(10.4\%), Congenital anomalies(CA) (10.1\%), Morbidity of the low birth weight newborns admitted to SNCU is low (2.2\%).

\section{Acknowledgements}

We are very thankful to Dr.G.S.RamaPrasad M.D. (Pediatrics, PGIMER), Principal, Kurnool Medical College, Kurnool, A.P. for allowing to do this research study. Also thankful to Dr.G.Sudhakar. M.D; Dch Professor of Pediatrics for his guidance, and finally to all mothers and babies of this study without them this study would not have been possible.

\section{References}

[1]. Vishnu bhat and adhisivam (2012). Trends and outcome of low birth weight (LBW) infants in India. The Indian journal of pediatrics doi: 10.1007/s12098-012-0922.

[2]. World Health Organization, International statistical classification of diseases and related health problems, tenth revision, World Health Organization, Geneva, 1992.

[3]. UNICEF/WHO, low birth weight: country, regional and global estimates, UNICEF, Newyork, 2004.

[4]. National Family Health Survey: 3 (NFHS: 3), 2005-06: India: Volume-1 Mumbai: IIPS. P. 225-6.

[5]. Idris MZ, Gupta A, Mohan U, Srivastava AK, Das V. Maternal Health and Low Birth Weight Among Institutional Deliveries. Indian J Com Med 2000; 25(4):156-60.

[6]. Kumar SG, Harshakumar HN, Jayaram S, Kotian MS. Determinants of Low Birth Weight: A Case Control Study in a District Hospital in Karnataka. Indian J Pediatr 2010;77 (1):87-9

[7]. $\quad$ Ghai OP, Essential pediatrics, 7th edition page no.96.

[8]. Emel Altuncu et al. The incidence of low birth weight in 5000 live born infants, Marmara Medical Journal 2006;19(2);46-51

[9]. Kayastha S, Tuladhar H, et al. Study of low birth weight babies in Nepal Medical College.

[10]. Were FN, Mukhwana BO, Musoke RN, Neonatal survival of infants less than 2000 grams born at Kenyatta National Hospital, (East African Medical Journal: 2002 79(2): 77-79)

[11]. Daynia E Ballot, Tobias F Chirwa and Peter A Cooper, Determinants of survival in very low birth weight neonates in a public sector hospital , Johannesburg, 2010.

[12]. Sritipsukho S, Suarod T, Sritipsukho P: Survival and outcome of very low birth weight infants born in a university hospital with level II NICU. J Med Assoc Thai 2007, 90:1323-9

[13]. Trotman H, Bell Y: Neonatal sepsis in very low birth weight infants of the west indies. West Indian Med J 2006 55:165-9

[14]. Velaphi SC, Mokachane M, Mphahlele RM, Beck-Arnold E, Kuwanda ML, Cooper PA: Survival of very low birth weight infants according to birth weight and gestational age in a public hospital .S Afr Med J2005, 95:504-9 